\title{
PRESENT ELEMENTS AND PROSPECTS FOR DEVELOPMENT THE SUSTAINABLE FARMING IN ROMANIA
}

\author{
Associate Professor PhD Burja Camelia,e-mail: cameliaburja@yahoo.com \\ Universitatea „1Decembrie 1918” Alba Iulia
}

\begin{abstract}
The sustainable farming constitutes a major component of the Common Agricultural Policy and could be a chance for developing the Romanian agriculture sector. It is obvious that Romanian economy and within it, the agriculture sector, is in urgent need of renovation and a realistically approach is to adopt a new development strategy, in which should be present the sustainability concept. The paper presents some aspects related to the general model of the sustainability, the present stage of the sustainable agriculture in Romania and identifies some necessary future directions for implementing this concept.
\end{abstract}

\section{Introduction}

The society progress is a continuous process, so that within economy there are necessary permanently changes and restructure actions which should to represent the ground of the better future.

Beginning with the Earth Summit of Rio de Janeiro (1992), the concept of the sustainable development was constantly on the politic agenda of the developed countries of the world. The globalization phenomenon also, the recently integration of Romania into the European Union have determined it to adopt the strategy of the sustainable development of the society, meaning to build a viable future both as economical and social perspective as ecological one.

Following the model of some countries with a vast experience in the sustainable development domain (Germany since 1969 promoted ample debates on the environment protection), Romania has to identify the main economic sectors on which to concentrate its efforts (Federal Environmental Agency, 2002). Meantime, it becomes necessary the elaboration of a national strategy for sustainable development of the economy which has to have a viable feature even that implies fundamentally changes both in theory and economic practice and in people mentality as well.

\section{The model of sustainable development}

In order to direct the economies of the EU membership countries towards the sustainable development model, at the European Union level has imposed the concepts and practices which have the role of stimulating the structural changes within society. So, it was selected the sectors which are directly implicated, were developed the base rules of using of some substances and materials within the economic activity, it has approached the problem of the environment considering a restrictive factor for the economic development, imposed the environment norms and also, outlined the necessary economic, ecological and social criteria for realizing the sustainable development.

It has to take into consideration many aspects for progressing in implementation of the sustainable development strategy:

- setting the objectives of the sustainable development model. These objectives can be defined taking into consideration the whole context of relations between the economic, social and ecological elements of any sector policies, so that the negative impact of the economic actions regards not only the ecological effects produced on the local level but also, the effects which could appear at the global level; 
- setting an economic and social environment which can promote the sustainable development. For developing the necessary changes, in the first, should to be analyzed the quality of the existent economic environment (efficiency, market mechanisms, private property, social inclusion) and then, the quality of the social and cultural system for identifying theirs limits and theirs grade of the adaptability;

- stimulating the restructure actions towards promoting the innovation processes both in the technological domain as in the social and economic aspects, and The $6^{\text {th }}$ Research and Innovation Frame Program (2003-2006) substantiated the needed objectives which have to be assume by any membership countries of the European Union concerning the technological innovations and theirs integration within the economic environment. There are necessary new technological processes and new structures which could preserve resources, meantime not polluting, improve the quality of people education who have to aware the importance of the economic model of the sustainable development and to form their capacity to implement it, stimulate the innovation capacity of the labour force who is the main creative factor, change the consume behaviour of the population towards those products, services and practices which are less harmful for the environment, change the values system, attitudes and life style according with the sustainable development objectives;

- implementing measures of the sustainable development model. The state has an important role in coordination the sector policies, education, setting the innovation strategy at the national level, directing the market economy to the ecological aspects and for realizing them, it can use various instruments like: economic and environment legislation which contains the European standards, introduction of the environment taxes in order to transfer the expenses of some unwished effects on the environment to polluting firms, using the pollution premises, expenses for environment protection etc. Meantime, at the companies level becomes necessary to adopt a behaviour grounded on the sustainable development principles which would permit them to adapt their production economies to requirements and opportunities provided by interaction between the productive sector and the environment protection (environmental management system, eco-audit, life cycle analysis, environmental performance assessment etc).

Considering the system conception of the sustainable development model, it can observe that such economy has in principal, economical reasons for its functioning namely, ensuring efficiency to satisfy the population and society demands. The way of realizing these requirements is in fact, the essence of the sustainable development concept. It imposes to take into consideration the demand of natural environment protection, as the economy functioning to ensure not only a quantitative increase but also, a qualitative one, permitting the next generations to develop them. The specific instruments which are used should to be both economic as ecological type.

The model of the sustainable development due to its objectives, actions and consequences produced, is very complex and can be realized only through its application in every economic sector which is related with the quality of the environment and the life quality.

\section{The stage of sustainable farming in Romania}

Being in a great measure directly related with the environment through the natural resources used for production, the agriculture is a sector with a strongly ecological impact. The adverse effects during the time generated on the natural environment appear in various kinds of water, air or soil pollution, illustrating the level extends of the life's quality and of the people's health. From these reason, the organization of the farming sector should to benefit by a coherent strategy based on sustainable development principles, which to contain the ecological conditions, not neglecting the economic and social aspects.

In Romania, only after initiated the legislative framework concerning the promoting of the organic farming (2000), has increased the interest to convert the conventional practices of culture plants, growing animals and processing products towards the practices of the sustainable agriculture, 
and many associations of ecological farming producers set up: Agroecologia, Asociaţia Română pentru Agricultura Durabilă, Bioterra, Societatea pentru Agricultură Ecologică, Ecorural. The guarantee of the products quality and of the respecting the principles of the sustainable farming are due to existence of the 12 certificated agencies (Gain Report, 2006). The certificated products will be identified on base of the label which proves the products type, meaning whether they are from organic provenience. Before the certification of the own products, the agricultural holdings have to implement the principles of the organic farming, that is, to pass a conversion period which is short enough in the Romanian case, only one or two years, due to the fable consumption of fertilizers and pesticides during the last 15 years. In consequence, the potential of the rapid growing of the organic farming sector could be significant.

In Romania, the conversion to the sustainable productive practices within the agricultural holdings is not very simple. Most regions have a poor infrastructure, there is no domestic market for organic products where farmers could sell their products at better prices, the possibility of financing the agricultural exploitations investments are reduced and concerning this aspect, up until now it, the opportunities to stimulate sustainable development were the pre-accession SAPARD funds and beginning with 2007, the rural development funds specific of CAP are in operation.

Being considered still an industrial-agrarian country due to the high weight of the countryside population (46\%) and of the greater dependence of its economy by the agricultural activities outputs (10\% of GDP), Romania is in a start phases of the sustainable agriculture implementation (Romanian Yearbook, 2006).

The great share of the labour force employed in agricultural sector can suggest the extensive character of it, also, practising of some technologies with a big labour consumption. These aspects besides promoting the conversion investments towards the ecological production practices can constitute a chance to develop the sustainable farming in Romania. Another negative aspect is fable agriculture productivity, that is the soil productivity represents only $30 \%$ by the productivity level of the EU-15, meantime the labour productivity is only $7 \%$ of the same indicator at the EU-15 level, so the Romanian agriculture sector can ensure only a small part of the agro-food products that are necessary to the population (Eurostat). The value of total agricultural imports needs a big financial effort (2424.8 million euro) that is 3 times greater than agricultural exports and contributes to unbalance the country's payments balance. The high share of agriculture in GDP (10\%) suggests also its outdated feature, the same indicator being in the majority of EU integrated countries much below $10 \%$ : Czech Republic $3 \%$, Estonia $4 \%$, Hungary $4 \%$, Latvia $4 \%$, Lithuania $6 \%$, Poland 5 $\%$, Bulgaria $9 \%$, Slovenia $3 \%$, Slovak Republic $3 \%$, Croatia $8 \%$ (European Yearbook).

However, the efforts made by Romania in the last years to encourage sustainable agriculture development are highlighted by an accelerated dynamic of specific indicators. Nowadays, there are about 4000 agricultural holdings organized in a sustainable manner, situated mostly in Transylvania (Bioterra owns $67 \%$ from total of organic farms and $68 \%$ from total of ecological surfaces of Romania) whose interest in developing organic agriculture is the high percentage of their export production (95\%) and advantages of higher prices on foreign markets.

In order to obtain ecological agro-food products, healthier for people and less harmful for the environment, the farmers should to organize their activity on base of the sustainable agriculture rules, that is:

- eliminate the use of any polluting technology;

- realize the production structure and crop rotation lands, in which the species plants and animals categories have to be very adaptable;

- continuously sustaining and amelioration of the natural fertility of the soil;

- integrate the animals growing in the crops production system;

- rationality using of the conventional energetic resources and replacing them with renewed resources, ensuring in the same time, their capacity of renewing;

- qualitative protection of not renewed resources; 
- application of those technologies which have to satisfy the demands of species, breeds and animals categories;

- preserve the biodiversity within the complex ecosystems;

- ensure the economic viability of farms;

- realize the safety and transparency for the consumers;

- promote the ecological and social services in agriculture.

The presented characteristics illustrate the importance of the agriculture sector for Romania, sector that is still an important economic factor due to its tasks, the high percentage in gross value added, implications for the regions, and protection of the ecosystems. In this situation, becomes very important the existence of a national strategy for the agricultural sector, which ensure implementing of the Communitarian model of the sustainable farming. The reality has demonstrated that this is the only viable model which can reconcile improvement of the competitiveness practices of the agricultural production with needs of preserve and develop the landscapes, protect the nature, so only it allows realizing an efficient agriculture, competitive and compatible with the environment, as well.

\section{Development directions of sustainable farming in Romania}

A very important phase of successfully implementing the sustainable agriculture in Romania is gathering the farming lands, over cut as result of the agricultural property reinstated after 1990, as that it will be created those conditions of a better performing of the agro-technique works and a better managing of the total natural resources, material, financial or human, as well, by which agricultural producers could dispose.

Due to reinstate the private property on the farming lands, have resulted many agricultural holdings smaller than 5 hectares which represent $91,6 \%$ by the arable land existed in private property or $54,5 \%$ from the entire arable land of the country, as practising the efficient management is hindered. If one takes into consideration the 2005's situation, in Romania existed almost 1,24 million holdings which have an economic dimension of 1 European Size Unit (ESU) and detained 10,3 million ha, the consequence being that Romanian agriculture has a subsistence character and farmers can not benefit by subsidies accorded by the European Union, the minimum dimension necessary of an agricultural holding to be eligible in the payment unique schema, is 1 ha (Benoist, 2007).

Another important demand of ensuring the sustainable farming is stimulation the increasing of the ecological surfaces.

The whole surface cultivated in an ecological way is 170000 ha and although it increased almost 10 times comparative with 2000, it represents less than $1 \%$ from the total agricultural land, meantime the organic cultivated areas in Europe are much greater. In 2006 Liechtenstein has the greatest weight of the agricultural surface ecological cultivated $26,4 \%$, followed by Austria with $13,6 \%$, Switzerland 11,3\%, Finland 7,3\%and between 5-7 \% there are many other countries like Sweden, Italy, Czech Republic, Denmark, Portugal, Estonia (Bonny, 2006).

The average dimension of the ecological surfaces of the EU-15 agricultural producers is 35,1 ha, as comparative with the very small lands extend of the Romanian farms (almost of them under $1 \mathrm{ha}$ ) illustrates that ecological agriculture practising in Romania is still in a beginning stage (GAIN Report, 2006). Although, at the European level ecological agriculture is considered a mean to sustain the smaller dimension of the holdings, in Romania it is necessary firstly, that holdings to transform into economic viable organisms, stimulating the increasing process of land dimension organic cultivated within a farm and then, converting the conventional practices towards the alternative ones which also, could ensure the environment protection.

At the European level as result of Common Agricultural Policy application has presented a continuous process of production specialisation and introducing the technological progress, in order to increase the productivity. Have to be diminished the negative consequences on environment and 
in this sense, the agricultural policy of the European Union (2000 Agenda) recommended application of the new technologies. In the last years, has increased specially, the role of the information and communication technologies in managing firms activities, Internet using in agricultural production and marketing organization, GPS using in farmlands management. In Romanian case, in order to new technologies could be applied, a necessary precondition is extending the information infrastructure to the rural areas, and this direction should be an essential element of the agriculture restructuring and modernization strategy.

- The firms' management on base the information and communication technologies demands development the expert systems of crops protection using or for business management. From point of view of the environmentally aspects there are important those expert systems which represent a support for decisional factors related to substances needed to ensure the crops protection or to fertilize them.

- The Internet could be use like a new marketing channel. This vast network allows making various e-commerce modalities in order to increase the business performance in any sector. Most known of them are products sales by businesses to consumers (B2C) which, generally, have a lower weight in the agricultural sector due to the alterable feature of some agricultural products (vegetables, fruit, animals products) and transactions between the firms (B2B) which in the agricultural domain have the greatest relevance due to the fact that agricultural products supported some conditioning, storage and transforming processes before to be sold. Introducing the Internet within agricultural transactions practice constitutes a concrete modality by which the producers could access to the whole national market, making also possible, products commercialization on the international market.

- Using the global positioning systems (GPS) and data processing systems can contribute to improvement of the agricultural lands cultivation. In Romanian case, using in agricultural practice the information technologies is conditioned by realizing a grater extend of the lands in the private or stat property and creating land maps, as the global positioning system (GPS) and geographical information system (GIS) could operate and identify the unitary land surfaces. The information about production conditions specific for soils allow creating data bases which could become support of performing a quality management and for practicing those crop systems that are compatible with environment.

Nowadays, in the European Union preoccupation for limiting the negative consequences of the agricultural activities has materialized in introducing some minimum management standards within a document entitled the Code of Good Agricultural and Environment Conditions, which has particularities according with the regional specific of every EU membership country. In this manner, the EU legislation focus on controlling the pollution level and environment protection and the concrete instrument of monitoring the application the GAEC standards, it is represented by global positioning systems.

For Romania the Code of Good Agricultural and Environment Conditions implies the distance detecting control of prohibit weeding crops emplacement (potatoes, maize, sun flower, sugar beet) on the arable lands that have an inclination more than $12 \%$ in order to prevent the soil erosion, and in the case slopes have still been cultivated, it controls if those lands were covered in the hinter time with autumn crops (wheat, barley) or with plants like clover, Lucerne, also detecting system should identify whether it was respected the standard by which the soil could be covered by natural vegetation, not ploughed after harvesting (EC 1782, 2003).

A present tendency manifested within the whole Europe is also, the production of the renewable raw materials, especially crops which can be used for obtaining energy. The production of the agricultural renewable raw materials becomes more important for the soil management. In this context, Romania disposes by agro climatic conditions favourable for such crops namely: sunflower that could be used in oils production destined to produce bio-diesel fuel (RME), potatoes, wheat or rape. Now, generally, these agricultural crops issues are lower than EU-15 ones, for 
example, the sunflower average production between 2000-2003 was $1060 \mathrm{~kg} / \mathrm{ha}$ that is $63 \%$ of the EU-15 average and for rape seeds the mean production represents $42 \%$ of the EU-15 indicator, better placed, without Bulgaria, being all the EU integrated countries (Eurostat).

A more rapid conversion of the conventional agriculture towards the organic and sustainable agriculture could be realized by using in a greater manner the financial stat support and the subsidies came from European funds. The received subsidies ensure improvement of the agricultural practices, as they play the role to financial sustain the holdings during the conversion period, balancing loses of the beginning phase until the organic products will be obtained and will result important further advantages from selling them at premium prices. Using the stat funds represented the instrument which permitted a strong growing of the organic agriculture in countries like Austria, Italy or France (Bonny, 2006). Nowadays, the European subsidies have the role to sustain the agricultural producers but only they use in practice the agro environment measures.

Although, Romania is still far away to tendencies outlined in the world into the sustainable agriculture practice, the future development of its agricultural sector is close related to this model. For the next years (2013 perspective) the foresights made for the European states suggest a positive image of the organic agriculture. It appreciates that the demand of organic products will increase due to the products quality and influence on the people health, animals and for the natural environment, on the other hand, a part of the European population considers organic agriculture as being the only solution to replace the products which provided by the industrialized agriculture. Also, the organic products market will continuous to increase. In the last period, in countries like Belgium, Czech Republic, Greece, Ireland, Slovenia, Spain which are emergent market countries, has became evident an increasing of the specific market by 5-10\% yearly, in the same time with modification of social status and incomes population increasing (Padel, 2005).

Within an economy with many possibilities of development, organic agriculture becomes an important option both for agricultural producers and for consumers as well, it can contribute to improve the productivity and efficiency, ensures the economic viability of rural areas and can reduce the negative impact on the environment. Taking into consideration the specific conditions of Romania, the recent tendencies manifested and the fact that it belongs to the European agricultural space, the perspective of establishing the sustainable development in Romanian agriculture sector becomes a strategic and necessary orientation.

\section{References}

1. Benoist G., Marquer P., Farm structure in Romania - 2005, Statistics in focus, Agriculture and Fisheries, no 60, 2007

2. Bonny S., Grignon I., Organic farming in Europe:Situation and Prospects, Notre Europe, 2006

3. Council Regulation (EC) no 1782/2003

4. European Statistical Yearbook, 2004

5. Eurostat website/agriculture/agriculture and fisheries/organic farming

6. Federal Environmental Agency, Sustainability in Germany, Creating a lasting environmentally compatible future, Erich Schmidt Verlang, Berlin, 2002

7. Gain Report RO6023, Organic Products Organic Agriculture in Romania, 2006

8. Padel S., Midmore P., The Development of the European Market for Organic Products: Insights from a Delphi Study, British Food Journal 107(8), 2005

9. Romanian Statistical Yearbook, 2006 